\title{
Intelligent charging pile design and operation management platform based on the Internet +
}

\author{
Tao Jiang ${ }^{1, a}$, Fen Qin ${ }^{1}$, Weiyong $\mathrm{Yu}^{1}$, Jian $\mathrm{Hu}^{1}$, Tiyin $\mathrm{Li}^{2}$ and Wei $\mathrm{Hu}^{1}$ \\ ${ }^{1}$ Hangzhou Kaida Electric Power Construction Co., LTD, Zhejiang, 310000, China \\ ${ }^{2}$ State Grid Power Supply Company of Zhejiang Yuhang, Zhejiang, 310000 China
}

\begin{abstract}
In this paper, the writer design a lifting charging pile and operation management platform based on Internet plus, aiming at solving the problem of structure and the function imperfections of the existing ordinary charging pile and background management system. Charging pile body adopts lifting structure and comprehensively utilizes sensing technology electronic technology and communication technology to real time monitor the running state parameters and running environment parameters of charging piles. In addition, charging pile adopts centralized management, regional management and user independent management of the three level of intelligent management to ensure the smooth construction and use of charging pile.
\end{abstract}

Keywords: charging pile; electric vehicle; internet plus; APP client.

With the rapid development of economic conditions, the car is becoming more and more popular in our country, energy shortage, vehicle emission and other issues are the main problems that threaten the survival of mankind [1]. In China's central and local intensive introduction of subsidies and other favorable policies under the catalysis, China's new energy automotive market continued to show a blowout state. And electric vehicles with its zero pollution, zero noise, driving a simple advantage has become an inevitable trend in energy conservation and improve the earth's environment [2].

With the size of the new energy vehicles continues to expand, charging infrastructure "forage" issue, charging difficult situation increasingly apparent, charging facilities not perfect, also seriously has restricted the development of new energy vehicles [3]. The existing ordinary charging pile and background management system not only the structure is not perfect, and the function is not sound and complete, not enough to ensure the construction of electric vehicle charging station smoothly [4]. Therefore, design a new intelligent charging piles and operation management platform to improve on the existing basis of its structure and function is of vital importance to guarantee the development of electric vehicle industry.

\section{Review of research status at home and abroad}

The charging pile can be divided into vertical charging pile and wall mounted charging pile [5]. Vertical charging piles without wall are suitable for outdoor parking or parking space. But the majority of them are exposed in the outside and exposed to the weather, protective property is not

\footnotetext{
${ }^{\text {a }}$ Corresponding author : kdjiangtao2016@126.com
} 
strong, need performance of strong waterproof, moisture-proof, anti-theft and anti-strike, and the larger area is easy to cause damage condition [6-7]. The wall mounted charging pile must rely on fixed wall, are suitable for indoor and underground parking. But the installation process is more complex and costly, and the main structure of a wall-mounted charging pile more complicated, is not conducive to disassembly and maintenance [8]. In charging pile management system, the existing charging pile management system only for a single charging station or some small charging pile project [9]. In the billing system, the current charging stations to ensure the normal operation of the charging station charging station charging management system is not yet mature products, Charging station and billing management systems are mostly designed for a charging station, communication protocols and communication interfaces is no uniform standard charging station and charge back billing system between the pile can be followed, and no information on the links between each charging station [10-11]. In the charging pile related technologies and standards, lack of charging power supply and battery system application integration technology and related standards and norms is still the bottleneck of the popularization and application of electric vehicles, to further the development of electric vehicle and charging facilities of unified planning brought great difficulties.

\section{Design of intelligent charging pile body and its network monitoring and management system}

\subsection{Design of intelligent charging pile network monitoring and management system}

Similar to the gas station, charging pile is also a point distribution and the various corners of the city, but its distribution density and area is far greater than the gas station. Aiming at how to increasing the charging pile management, timely understanding of the charging pile of health and the use of the state, providing the charging pile the latest state information for managers and users, better monitoring and management of the charging pile, In this paper, we design three level monitoring and management network to realize the intelligent management of the charging pile, and network structure as shown in Figure 1. The third level of the network are for charging users through the mobile phone APP software independent of the agreement with the charging pile to complete electric car charging. Second level network are regional monitoring and management platform, inspect each charging pile in the management area regularly. Second level network use unattended mode, each charging pile collection status including health status, working status, etc, and store the state data of each charging pile. The first level of the network is centralized monitoring and management platform, Timing and regionally communicate with monitoring and management platform. The first level of the network uses unattended way, collect and summarize the data of charging pile of regional monitoring and management platform in a period of time, and process these massive data. The data provide decision-making basis for the construction planning, operation and maintenance of charging pile. 


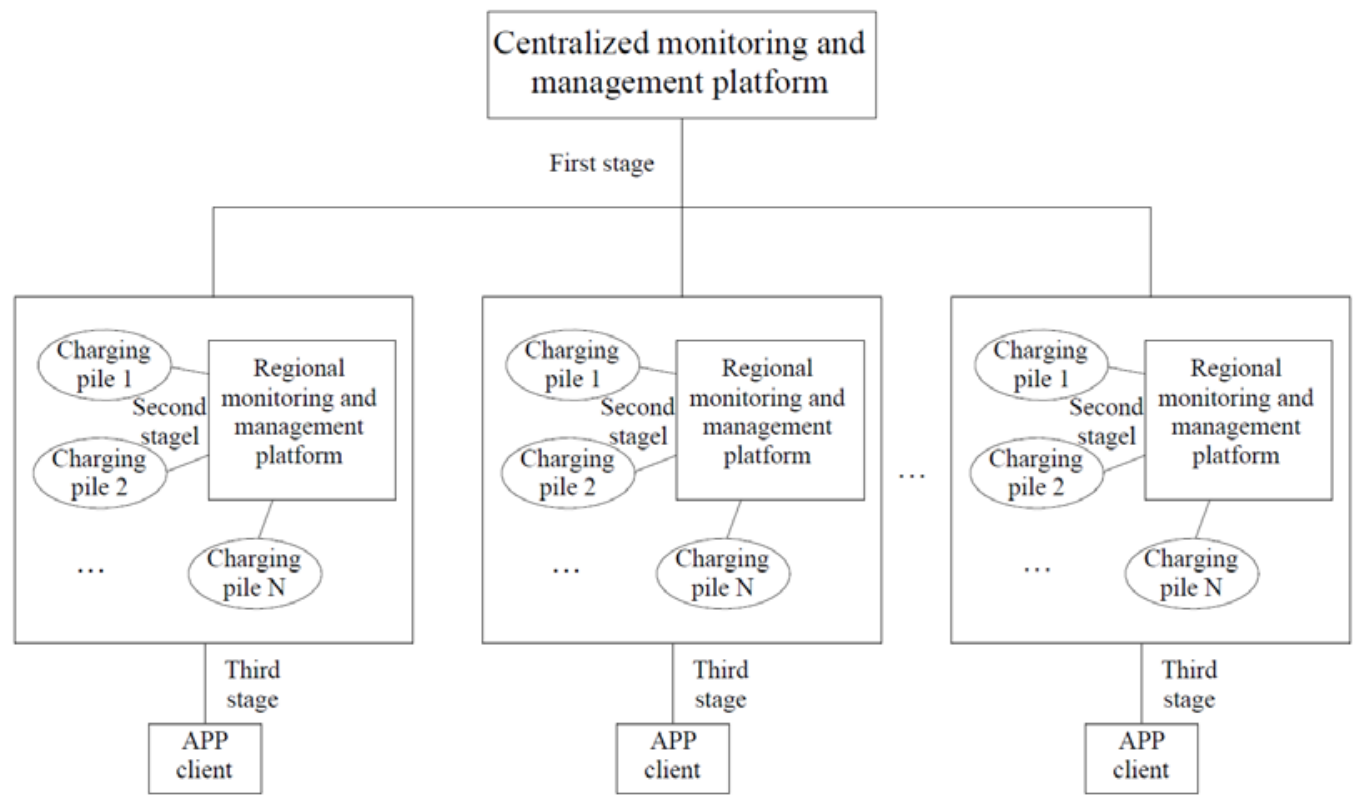

Figure 1. Intelligent charging pile integrated monitoring network system

\subsection{Design of charging pile body structure}

Intelligent charging pile body structure include the following three main parts: lifting charging pile body, intelligent charging control module and intelligent charging pile maintenance and back-end information integration platform. Charging pile body structure as shown in Figure 2 dashed box.

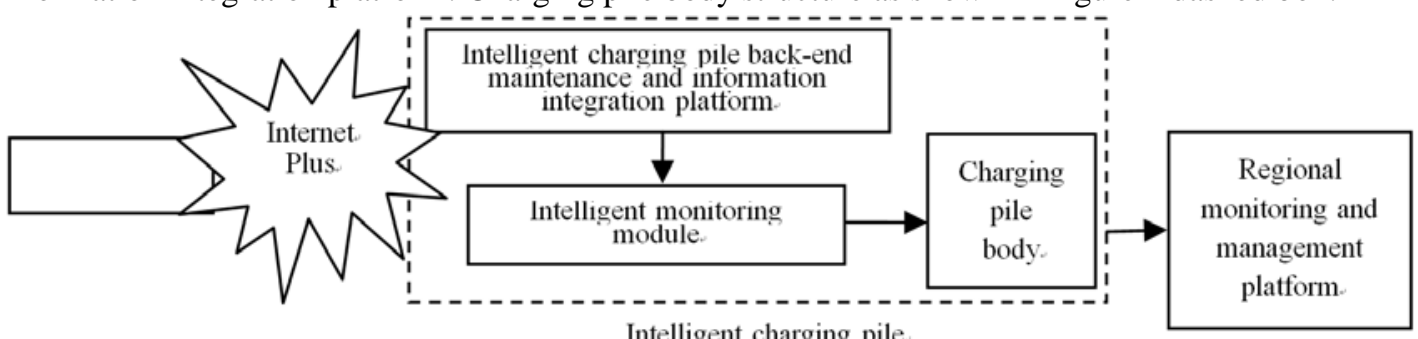

Intelligent charging pile.

Figure 2. Intelligent charging pile body structure

By changing the structure of the new intelligent charging pile, it can save the area of the pile. Through the design of ancillary products, users can easily search the nearest charging pile and view its full state, and can be online booking and payment. Through improving the function of the backstage management system, it can not only realize the function of monitoring the running state of the charging pile, but also can realize the function of human-computer interaction, accounting, user card management and security protection. Improvement of charging pile structure and the function can promote the development of electric vehicle industry, and to a certain extent, is conducive to the country's energy conservation and emission reduction.

\section{Design of intelligent charging pile}

\subsection{Mechanical structure design of lifting charging pile}

The mechanical structure of the lifting charging pile includes three parts, the lifting device, the charging pile and the sealing device, the mechanical structure of charging pile is shown in figure 3 . 
Under the condition of no use, the charging pile is arranged under the ground, and the sealing plate of the sealing device is flush with the ground. When someone is in use, the charging pile is aroused from the underground by the mobile phone APP software, and the sealing device is opened, and the lift can lift the charging pile up to the ground, the user operate to charge, charging the completion of the charging pile once again sink into the ground to return to normal. Charging pile up the ground after the effect diagram is shown in figure 4.

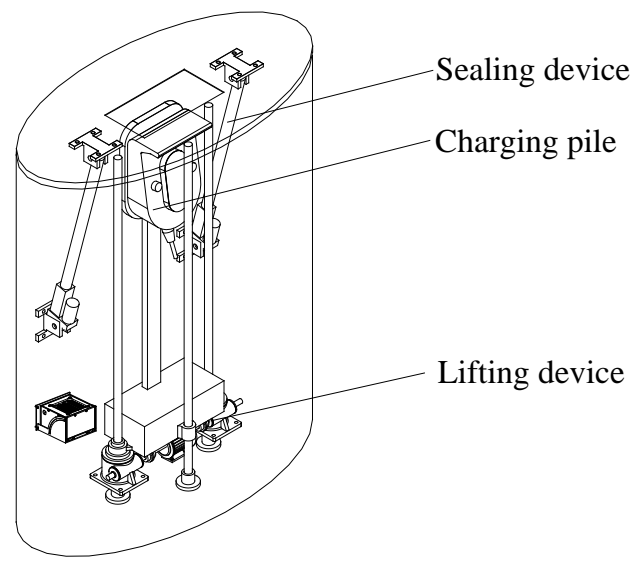

Figure 3. Schematic diagram of mechanical structure

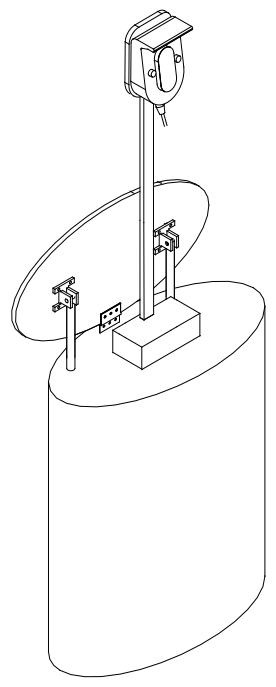

Figure 4. Effect drawing of charging pile

Lifting device to worm gear screw lift is main structure, the specific structure as shown in figure 5. Power is located in the middle of the two worm screw elevator motor output, the output shaft is connected with the internal worm of the elevator through the shaft coupling. The worm and the worm wheel are driven to rotate so as to drive the lead screw to rotate, so that the charging pile and the elevator can rise and fall as a whole. The connection method has high precision, stable movement, high transmission efficiency and self-locking function. The guide rod is used for guiding the positioning, and the lifting nut is connected with the charging pile and the lifting mechanism, and the elevator motor is connected with the elevator motor to rise and fall, so that the synchronous lifting is convenient for personnel to repair and clean up the debris. In the course of using the screw, the screw rod has the advantages of low noise, smooth transmission, flexible use, etc. But also to ensure the use of safe, lift setting the automatic locking function, when there is a problem with the operation of 
equipment, lift and can self-lock and stop motion, in a certain extent, to protect the production environment and personnel safety.

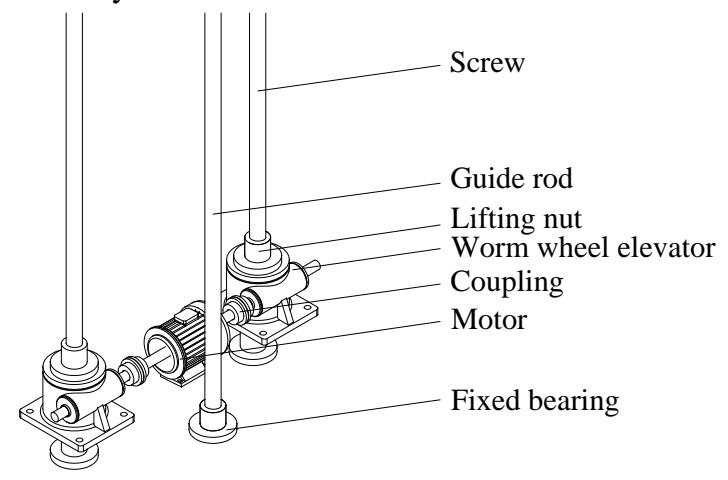

Figure 5. Schematic diagram of mechanical structure of charging pile

The sealing device comprises a shell body and an electric push rod, both ends of the electric push rod are fixed on the shell body and the shell sealing cover through hinges, and the electric push rod extends when the electric push rod is extended, and the sealing cover is opened, the electric push rod is shortened, and the sealing cover is closed gradually. The advantages of long distance control, centralized control, high power, high load and low noise are realized. The elliptical shell is beautiful and effective use of space. The shell is the carrier of the charging pile sinking into the ground, and it is also the main equipment of waterproof, dust, anti-collision, anti-abrasion, anti-theft and ant-interference.

\subsection{Design of intelligent charging pile back-end monitoring module}

Electric vehicle charging pile back-end monitoring module should provide perfect distribution monitoring, charging surveillance, security monitoring and other functions, realize centralized monitoring and control management of charging equipment, power distribution equipment and other equipment. There will be a display main body of the charging pile, on the screen show only the real-time information of the user attention, such as the fault information, charging time, charging time remaining, payment information and charging complete tips and so on. Some electrical parameters, such as voltage, current and comprehensive information, and the use of information by users, harmonic information, which are not displayed on the electronic screen, these information will be sent to the background maintenance and information integration platform, and automatically integrate and transfer the information to a centralized monitoring and management platform.

Charging pile monitoring module is mainly to monitor the following parameters:

(1) Electrical parameter monitoring. Online real-time monitoring and recording of the electric vehicle charging pile of active power, reactive power, apparent power, power factor, voltage deviation, voltage, current harmonic content, total distortion rate and voltage and electrical parameters such as current harmonics, Then complete the system analysis of various power quality problems.

(2) Fault detection. According to the leakage, short circuit, overvoltage, under voltage, transition and other protection detection function of the charging pile itself, when the charging pile with the above problem is detected, charging pile will not rise from underground bunkers, or more faults are discovered in charge, charging pile alarms and automatic sinks underground bunkers to ensure safe use of charging pile.

(3) Integrated condition monitoring. By monitoring the whole harmonic and inter harmonic currents injected into the power grid, the harmonic model of charging piles based on the coupling admittance matrix is established. To analyze the influence of the harmonic interaction of multiple charging piles in the charging station, and avoid the harm caused by the voltage flicker of the power 
grid and the equipment of the harmonic compensation. Study the harmonic analysis method, the harmonic diversity, the attenuation effect and the rise effect caused by the active filter.

\subsection{Design of the back-end maintenance and information integration platform for charging piles}

Based on the development status of charging pile management platform at home and abroad, an intelligent charging pile monitoring and information integration platform is developed, which online monitor the running state of the charging pile, and realize the comprehensive state monitoring of the charging station, provide a large number of reliable evaluation data and strategies for the operation planning of the charging station and the inspection and maintenance.

(1) Monitoring function. Monitoring function is the most basic function of charging pile monitoring system, which is mainly divided into monitoring function and control function:

(2) Interactive function. Interaction function refers to the function of interaction between the monitoring system and the human and the monitoring system, which mainly includes the function of human-computer interaction interface. Mainly includes the graphic combination, audio-visual integration and diversification of data display mode, graphic interface, audio and video monitoring interface, keyboard, mouse and other convenient operation control method and equipment for external, keyboard and so on occasion of man-machine interface.

(3) Billing and user card management.

(4) Safety protection function. Safety protection function is to monitor the system in order to protect the charging pile, so that the charging pile in the operation of the abnormal situation and take appropriate measures to achieve the protection of charging pile equipment function. Mainly include: anti-overheating, anti-impact, anti-theft.

(5) Communication function. Implement information integration platform, respectively, with the charging pile and the user side of the mobile phone APP information interaction.

\subsection{Development of APP application software for charging pile}

With the popularity of smart phones, APP client software has been applied to all aspects of daily life. The system design the 2 versions of the client software, respectively, to support the operating system IOS V7.0.0 and above version and Android V2.3.3 and above version, the overall design is the C / S system structure, client view layer contains a plurality of function, to provide better flexibility and strong expansion of capacity.

App client software according to user selection function calls to the business logic module, logic module is responsible for organization of business process, and call the business entity module, through a gateway server interface (or platform server interface) with gateway server (or server) to exchange information, have the following functions:

(1) Map display function. Map is the most basic function of charging pile APP, used to visually display the location of charging piles in the area.

(2) State display function. Display the status of all the charging piles in the area in the form of a map or a form with the identification of different colors. Green said charging pile idle state, yellow means is the use of state, red indicates a fault condition, gray is the maintenance and overhaul.

(3) Optimal path query and navigation. Charging pile APP system automatically query and display the area of the optimal charging pile path, and provide the line navigation of each charging pile.

(4) Reservation function. Support online booking, when charging pile in a certain period of time have been others reservation, reservation information will be displayed in the details of the charging pile, such as reservation beyond the time for a certain period of time did not reach, automatic cancel reservation information.

(5) Control function. Reaches the charging pile, by scanning the two-dimensional code, establishment and charging pile of communication links, through app control will be the "wake up" 
that rises to the ground to charge, payment, and so on, and then the sunk into the ground. These processes are through the realization of control app.

(6) Payment and settlement function. Support online payment, can be carried out through the mobile phone charges transfer or Ali-pay, We Chat and other three party payment platform, intelligent quota, timing charging etc.

\section{Conclusions}

(1) New intelligent charging pile by changing the structure, effectively save the floor area. Optimizing background management system can not only realize charging pile running state, improvement of monitoring and charging pile structure and function also can promote the development of electric vehicle industry, and conducive to the country's energy saving and emission reduction in a certain extent.

(2) New intelligent charging pile uses the integrated monitoring network system, uses three levels of monitoring and management network to realize the intelligent management of the charging pile, to ensure that the regional monitoring of the charging pile normal operation and data acquisition in the planning and construction of charging pile up decision-making.

(3) A new intelligent charging pile application of large data platform and "Internet plus" technology, in the background of management, analyzes the charging information integration platform not only for the information collected, and integrate with the charging pile information integration platform and user APP. The information integration platform and the user side of the mobile phone APP can use the "Internet plus" to better realize the online transmission of information, not only convenient, but also to keep pace with the times.

\section{References}

1. ZHANG Yong,PU Yongjian,SHI Lefeng. Analysis on Electric Vehicle Charging Infrastructure and Government Strategy [J]. China Soft Science, 82(06):167-181(2014).

2. XUE Fei, LEI Xian zhang, ZHANG Yebiao,etc. A Brand-New Approach of Connecting Electrical Vehicles with Smart Grid from Vehicle-to-Grid Mode to Battery-to-Grid Mode [J]. Power System Technology, 36(2): 29-34(2012).

3. OUYANG Ming-gao. Technology Strategy and R\&D Progress of Automotive New Energy and Powertrain [J]. Transactions of CSICE, S1:107-114(2008).

4. ZHANG Yun, LU Jiazheng,LI Bo. New Electric Vehicle AC Charging Spots Using Active Power Filter [J]. High Voltage Engineering, 37(01):150-156,(2011).

5. SUN Xiaohui,LIU Kai,ZUO Zhi. A Spatiotemporal Location Model for Locating Electric Vehicle Charging Stations [J]. Progress in Geography, 31(06):686-692(2012).

6. SAN Chenjun, AI Qian. Coordinated Charging Control of Plug-in Electric Vehicle Charging Station Based on Multi-Agent System Control Framework [J]. Electrical \& Energy Management Technology, 442(01):61-65(2014).

7. Xiao Xiangning,Wen Jianfeng,Tao Shun,etc. Study and Recommendations of the Key Issues in Planning of Electric Vehicles' Charging Facilities [J]. Transactions of China Electrotechnical Society, 29(08):1-10 (2014).

8. GAO Ciwei, ZHANG Liang. A Survey of Influence of Electrics Vehicle Charging on Power Grid [J]. Power System Technology, (02):127-131(2011).

9. DONG Zhaoyang,ZHAO Junhua,WEN Fushuan,etc. From Smart Grid to Energy Internet:Basic Concept and Research Framework [J]. Automation of Electric Power Systems, 38(15):1-11(2014).

10. Sortomme E, El-Sharkawi M A. Optimal Charging Strategies for Unidirectional Vehicle-to-Grid[J]. IEEE Trans on Smart Grid, 2(1):131-138(2011).

11. MENG Xiang jun,LIANG Tao,WANG Xingguang,etc. Design and Implementation of Electric Vehicle Intelligent Charging Pile [J]. Information Technology and Informatization, (6):58-61(2011). 